\title{
Mechanism of Nucleation and Precipitation in Li Containing Al-Zn-Mg-Cu Alloys
}

\author{
B.C. Wei', C.Q. Chen ${ }^{2}$, Y.J. Gu' ${ }^{2}$, Z. Huang ${ }^{2}$ and Y.G. Zhang ${ }^{2}$ \\ ${ }^{1}$ National Microgravity Laboratory, Chinese Academy of Sciences, Institute of Mechanics, \\ Beijing, 100080, China P.R. \\ ${ }^{2}$ Department of Materials Science and Engineering, Beijing University of Aeronautics and \\ Astronautics, Beijing, 100083, China P.R.
}

Keywords: Ageing Behavior, Al-Li-Zn-Mg-Cu Alloys, Mechanical Properties, Microstructure

\begin{abstract}
Investigations on the aging hardening behavior of four $\mathrm{Al}-\mathrm{Li}-\mathrm{Zn}-\mathrm{Mg}-\mathrm{Cu}$ alloys were carried out using differential scanning calorimetry, transmission electron microscopy and hardness measurement. It is shown that the addition of $\mathrm{Li}$ inhibits the formation of $\mathrm{Zn}$-rich G.P. zones in Al$\mathrm{Zn}-\mathrm{Mg}-\mathrm{Cu}$ alloys. The dominant aging hardening precipitates is $\delta^{\prime}\left(\mathrm{Al}_{3} \mathrm{Li}\right)$ phase. Coarse $\mathrm{T}$ $\left((\mathrm{AlZn})_{49} \mathrm{Mg}_{32}\right)$ phase, instead of $\mathrm{MgZn}$, precipitates primarily on grain boundaries, and provides little strengthening. The multi-step aging involving plastic deformation introduces in the matrix a high concentration of structural defects. These defects play different role on the nucleation of $\mathrm{Zn}$ rich G.P. zones in different alloys. For the Li free alloy, structural defects act as vacancy sinks and tend to suppress the homogeneous precipitation of G.P. zones, while for the Li containing alloys, these defects promote the heterogeneous nucleation of G.P. zones and metastable $\mathrm{MgZn}_{2}$. A significant aging hardening effect is attained in deformed $\mathrm{Li}$ containing alloys due to the extra precipitation of fine $\mathrm{MgZn} 2$ in the matrix combined with deformation hardening.
\end{abstract}

\section{Introduction}

Al-Li base alloys have received considerable attention as potential lightweight replacements for conventional Al-base alloys in aerospace applications. However, the development of Al-Li alloys was limited by the poor ductility and toughness. Extensive research has identified the cause of fracture toughness and ductility deficiencies, and several practical solutions have been suggested. One of these attempts is to affect the intrinsic slip behavior of the matrix by introducing additional precipitate particle. Alloying elements have been added to Al-Li base alloys to introduce multiple precipitation reactions, which may promote homogeneous slip distribution. A wide range of alloy system has been studied over recent years. Most of the development has been on $\mathrm{Al}-\mathrm{Cu}-\mathrm{Li}$, Al-Cu$\mathrm{Mg}-\mathrm{Li}$ and $\mathrm{Al}-\mathrm{Mg}-\mathrm{Li}$ alloys [1 5]. There is much less information on $\mathrm{Li}$ containing $\mathrm{Al}-\mathrm{Zn}-\mathrm{Mg}-\mathrm{Cu}$ alloys, even though the Al-Zn-Mg-Cu alloys are the highest strength commercial aluminum alloys.

Huang and Sodergren et al. have studied the effect of $2 \sim 2.5 \% \mathrm{Li}$ addition on the aging responses of 7075 and 7029 alloys $[6,7]$. They reported that the sole hardening precipitate in $7000+\mathrm{Li}$ alloys was $\delta^{\prime}\left(\mathrm{Al}_{3} \mathrm{Li}\right)$. The coarse $\mathrm{T}\left[(\mathrm{Al}, \mathrm{Zn})_{49} \mathrm{Mg}_{32}\right]$ phase, instead of fine $\eta^{\prime}$, precipitated heterogeneously. The lithium addition did not increase the strength of the base alloy, while it markedly decreased tensile elongation.

A nucleation mechanism involving Li-vacancy clusters was suggested, according to which the preferential clustering of $\mathrm{Li}$ atoms and vacancies appears to reduce the effective vacancy concentration and suppress the diffusion of $\mathrm{Zn}$ and $\mathrm{Mg}$ atoms, accordingly modify the nucleation mode and subsequence precipitation process.

It is well known that the high properties of $\mathrm{Al}-\mathrm{Zn}-\mathrm{Mg}-\mathrm{Cu}$ alloys are obtained through a complex thermomechanical treatment including a solution treatment, a quenching and a multi-step aging treatment. The influence of the introduced dislocations on mechanical properties is often a decrease in hardening response, but an increase in hardening properties has also been reported [8 11].

The purpose of the present paper is to investigate the effect of plastic deformation on the 
nucleation and precipitation in $\mathrm{Li}$ containing $\mathrm{Al}-\mathrm{Zn}-\mathrm{Mg}-\mathrm{Cu}$ alloys, and to understand the aging hardening mechanism in different aging conditions. Large plastic deformation amount is used in this work to introduce in the matrix high concentration of structural defects, and may promote the heterogeneous precipitation of Zn-rich phases in the matrix. Moreover, the relative low total solute level is selected in order to receive good comprehensive properties.

\section{Experimental Procedure}

The chemical compositions of the alloys investigated are shown in Table 1. The alloys were prepared from high purity metals, melted and cast under argon atmosphere, homogenized at $793 \mathrm{~K}$ for 24 hours, then forged and rolled at $723 \mathrm{~K}$ to the final gauge of about $2 \mathrm{~mm}$. Specimens were solution heat treated at $798 \mathrm{~K}$ for 30 minutes followed by water quenching.

Table 1 Chemical composition of the alloys (wt.\%)

\begin{tabular}{c|c|c|c|c|c|c|c|c}
\hline Alloy & $\mathrm{Li}$ & $\mathrm{Zn}$ & $\mathrm{Mg}$ & $\mathrm{Cu}$ & $\mathrm{Mn}$ & $\mathrm{Zr}$ & $\mathrm{Si}, \mathrm{Fe}$ & $\mathrm{Al}$ \\
\hline $\mathrm{A}$ & 1.81 & 2.88 & 1.45 & 0.98 & 0.32 & 0.11 & $<0.05$ & Bal. \\
\hline $\mathrm{B}$ & 1.80 & 2.56 & 1.45 & 1.90 & 0.32 & 0.12 & $<0.05$ & Bal. \\
\hline $\mathrm{C}$ & 2.12 & 3.56 & 1.43 & 1.02 & 0.33 & 0.12 & $<0.05$ & Bal. \\
\hline $\mathrm{D}$ & - & 3.94 & 1.62 & 1.02 & 0.31 & 0.12 & $<0.05$ & Bal. \\
\hline
\end{tabular}

The hardness was determined by the Vickers test using $50 \mathrm{~N}$ load. The transmission electron microscopy (TEM) was performed on a H-800 operating at $150 \mathrm{KV}$ with the foil normal to the through-thickness direction of the sheet. The differential scanning calorimetry (DSC) was undertaken in a Perkin-Elmer DSC7, and the specimen were placed in aluminum pans at a controlled heating rate of $10 \mathrm{Kmin}^{-1}$.

\section{Results and discussion}

\subsection{One-step aging}

\section{TEM results}

Artificial aging at different temperature was carried out immediately after quenching of the four alloys. The precipitation structure of the alloy D after $76 \mathrm{~h}$ at $373 \mathrm{~K}$, is shown in Fig. 1(a). The Li free alloy shows typical microstructure of $\mathrm{Al}-\mathrm{Zn}-\mathrm{Mg}-\mathrm{Cu}$ alloys, consisting of very fine G.P. zones and $\eta^{\prime}\left(\mathrm{MgZn}_{2}\right)$ in the matrix, together with a little coarser $\mathrm{MgZn}_{2}$ along the grain boundaries. The PFZs near the grain boundaries is not visible.
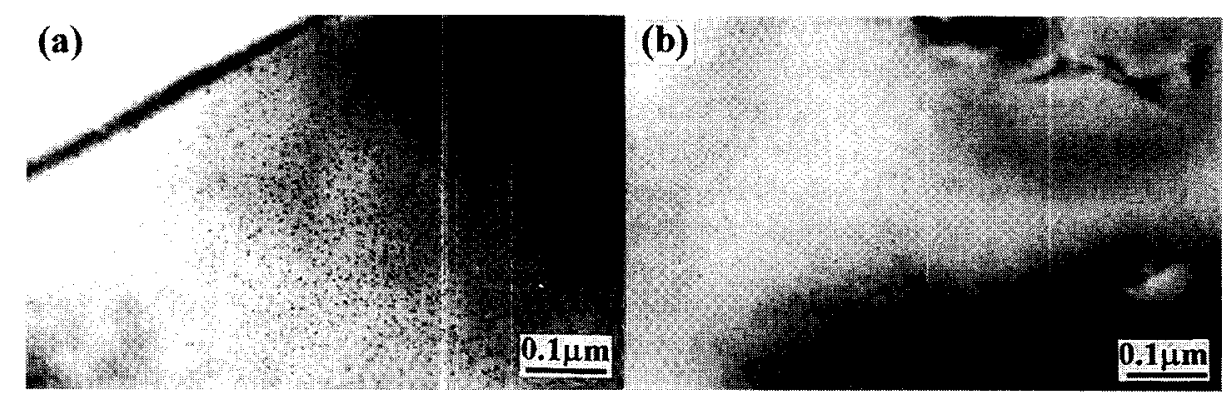

Fig. 1 Microstructure of the alloys aging at $373 \mathrm{~K}$ for $76 \mathrm{~h}$
a) $\mathrm{BF}$ image, alloy $\mathrm{D}\left(\mathrm{B}=<110>_{\mathrm{Al}}\right)$
b) $\mathrm{BF}$ image, alloy $\mathrm{A}\left(\mathrm{B}=<110>_{\mathrm{Al}}\right)$

The microstructures of the $\mathrm{Li}$ containing $\mathrm{A}, \mathrm{B}$ and $\mathrm{C}$ aged for $76 \mathrm{~h}$ at $373 \mathrm{~K}$ show identical precipitation feature, as shown in Fig. 1(b), consisting mainly of fine $\delta^{\prime}$ and heterogeneous 
precipitated $\mathrm{Al}_{3} \mathrm{Zr}$ phase. No precipitate reflections other than the superlattice reflection from the $\delta^{\prime}$ particles were detected in electron diffraction patterns for samples aged up to $100 \mathrm{~h}$.

Fig. 2 shows the microstructure of the alloys aged at $433 \mathrm{~K}$. The coarse $\eta$ and $\eta^{\prime}$ phases become dominant in the Li free alloy aged for $40 \mathrm{~h}$ (Fig. 2a). Meanwhile, the grain boundary precipitates coarsening, which leads to an increasing width of PFZs to about $70 \mathrm{~nm}$.

Peak aging of $\mathrm{Li}$ containing alloys (aging for $40 \mathrm{~h}$ at $433 \mathrm{~K}$ ), resulted in extensive precipitation of $\delta^{\prime}$ phase (Fig. 2b). In addition, fairly coarse particles precipitate both on dislocations in the matrix and at grain boundaries (Fig. 2c).
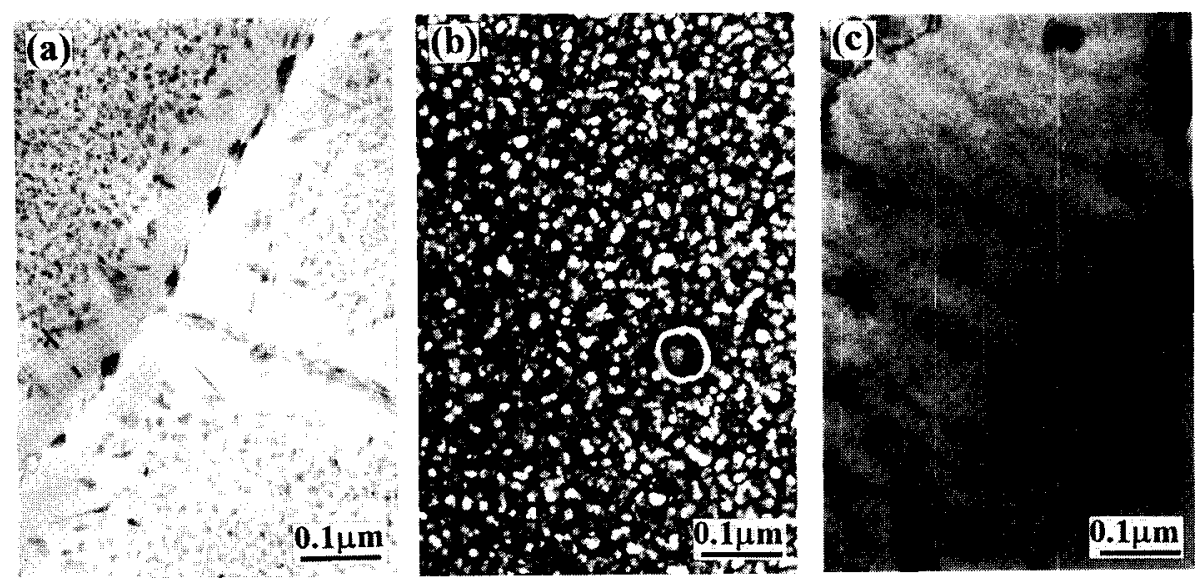

Fig. 2 Microstructure of the alloys aging at $433 \mathrm{~K}$
a) $\mathrm{BF}$ image, alloy $\mathrm{D}\left(\mathrm{B}=<100>_{\mathrm{A}}\right)$
c) $\mathrm{BF}$ image, Alloy $\mathrm{C}\left(\mathrm{B}=<112>_{\mathrm{Al}}\right)$
b) $\mathrm{CDF}$ image of $\delta^{\prime}$ phase, alloy $\mathrm{C}\left(\mathrm{B}=<110>_{\mathrm{Al}}\right)$

\section{DSC results}

An overview of the precipitation in the alloys can be obtained from the DSC curves. In Fig. 3, the DSC thermograms are shown for all the four alloys after quenching and extended natural aging. The main features of the Li free alloy are: a endothermic peak at $400 \sim 420 \mathrm{~K}$ due to the dissolution of G.P. zones and precipitate precursors formed during natural aging. After this dissolution there is an exotherm at $520 \mathrm{~K}$ due to the precipitation of metastable $\eta^{\prime}$ and equilibrium $\eta\left(\mathrm{MgZn}_{2}\right)$ phases. Following there are two endothermic peaks, in which the earlier at $550 \mathrm{~K}$ is from the dissolution of $\eta^{\prime}$ precipitates, and the later over ihe temperature range $570 \mathrm{~K} \sim 600 \mathrm{~K}$ is due to the dissolution of $\eta$ particles.

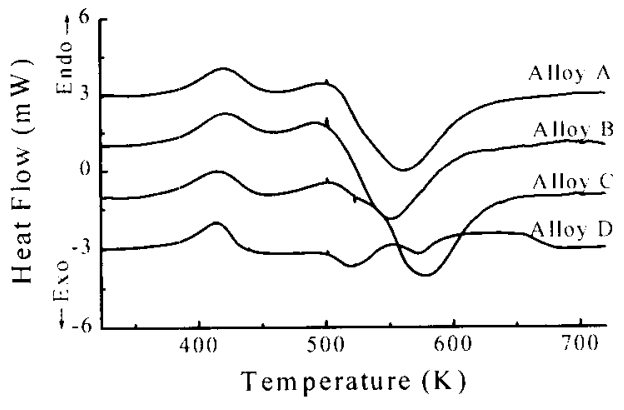

Fig. 3 DSC traces of the alloys after quenching and natural aging

The initial feature of the $\mathrm{Li}$ containing alloys is a endotherm at $400 \sim 420 \mathrm{~K}$ caused by the reversion of sub-critical diameter $\mathrm{Al}_{3} \mathrm{Li}$ [12]. This endothermic peak is at same temperature as that of the Li free alloy, but in different shape. The Li containing alloys have no precipitation exotherm of $\mathrm{MgZn}_{2}$. Instead they show a big endothermic peak at $550 \sim 580 \mathrm{~K}$. This suggests a new phase is precipitated. This phase is suggested to be the body centered cube $T\left((\mathrm{AlZn})_{49} \mathrm{Mg}_{32}\right)$ according to the selected area diffraction results. 


\section{Hardness response}

Hardening curves for one-step aging, as shown in Fig. 4, illustrate the aging response of the alloy at $373 \mathrm{~K}$ and $433 \mathrm{~K}$ respectively. The rate of hardness increase for the Li containing alloys at $373 \mathrm{~K}$ does not approach a saturation value up to $100 \mathrm{~h}$, and are markedly retarded compared with that for the $\mathrm{Li}$ free alloy (Fig. 4a). While at $433 \mathrm{~K}$, the aging responses of $\mathrm{Li}$ containing alloys are much stronger (Fig. $4 \mathrm{~b}$ ). This can be attributed to the fact that the additions of Li remarkably alter the precipitation behavior of the $\mathrm{Al}-\mathrm{Zn}-\mathrm{Mg}-\mathrm{Cu}$ alloy. The $\delta^{\prime}$ phase becomes dominant precipitated phase in the Li-containing alloys and the homogeneous precipitation of the Zn-rich phases is suppressed. Since $\delta^{\prime}$ phase nucleates and grows slowly at $373 \mathrm{~K}$, the age hardening rate of Li containing alloys is greatly decreased. While aging at $433 \mathrm{~K}$ leads to the extensive precipitation of $\delta^{\prime}$ phase which compensates the strength/hardness loss caused by the heterogeneous precipitation of Zn-rich phases, thus the Li containing alloys show a little higher peak hardness than that of the Li free alloy at $373 \mathrm{~K}$.
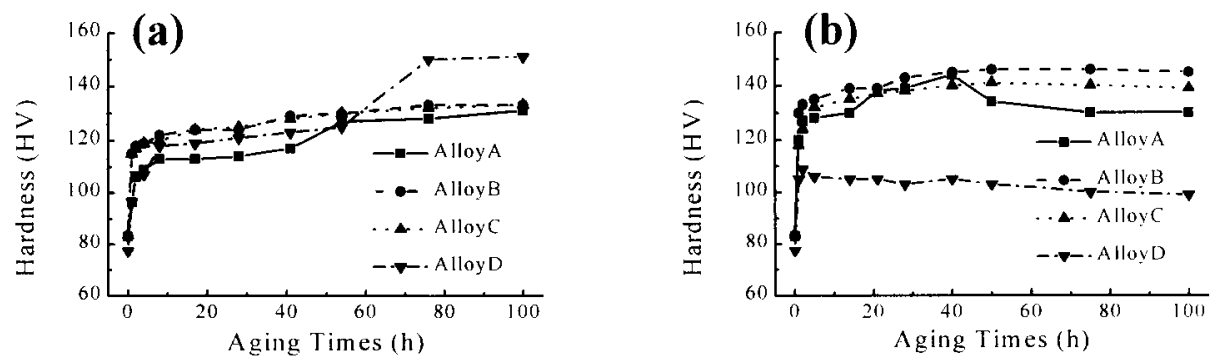

Fig.4 Aging hardening curves of Al-Li-Zn-Mg-Cu alloys a)at $373 \mathrm{~K}$ b)at $433 \mathrm{~K}$

\subsection{Multi-step aging}

From the one-step aging results it can be seen that the expected multi-precipitation is not attained in the $\mathrm{Li}$ containing $\mathrm{Al}-\mathrm{Zn}-\mathrm{Mg}-\mathrm{Cu}$ alloys because of lacking effective nuclei. Consequently, plastic deformation and two-step aging are carried out after quenching, aims to promote the precipitation of Zn-rich phases in the matrix. Plastic deformation increases the quench-in structural defect concentration, and may encourage the heterogeneous precipitation of $\mathrm{Zn}$-rich phases. Two-step aging involving the nucleation treatment at $353 \sim 373 \mathrm{~K}$, and later treatment at $423 \mathrm{~K}$ aims to accelerate the precipitation of $\delta^{\prime}$ and to ensure that heat treatment duration is commercially acceptable.

\section{TEM results}

After quenching, the samples of all the four alloys, were cold rolled 20,40 and $60 \%$ respectively, then pre-aged at $353 \sim 373 \mathrm{~K}$ for $8 \mathrm{~h}$ (alloy $\mathrm{A}$ and $\mathrm{B}$ at $353 \mathrm{~K}$, alloy $\mathrm{C}$ at $363 \mathrm{~K}$ and alloy $\mathrm{D}$ at $373 \mathrm{~K}$ respectively), and finally aged at $423 \mathrm{~K}$.

The microstructure of the $20 \%$ pre-deformed and peak-aged alloy $\mathrm{C}$ was shown in Fig. 5. It can be seen that the quantity of the large particles formed at grain boundaries is reduced compared with that of the undeformed alloys, and the distribution of precipitates in the matrix

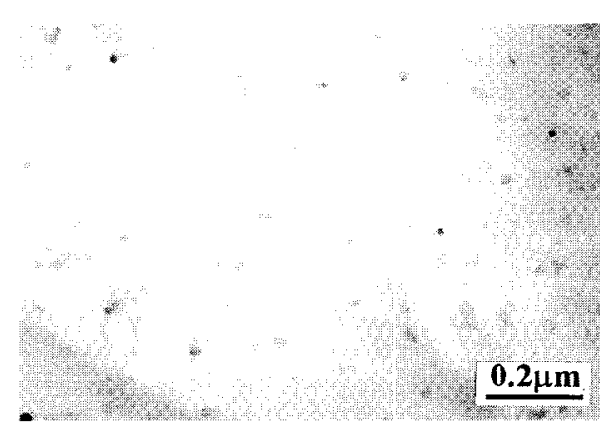

Fig. 5 Microstructure of multi-step aged alloy $\mathrm{C}$ tends to be homogeneous and fine. However the $\mathrm{Zn}$-rich phase in the matrix in the Li containing alloy is still much sparse 


\section{DSC results}

The DSC curves of the $0 \sim 60 \%$ deformed and natural aged Li free alloy are shown in Fig. 6a. It can be seen that the plastic deformation modified the precipitation behavior of the Li free alloy. The deformed alloys have no endothermic peak at around $400 \mathrm{~K}$ and only show the exotherm due to the precipitation of $\eta^{\prime}$ and $\eta$ phases, followed by a wide endotherm from the dissolution of $\eta^{\prime}$ and $\eta$ particles.
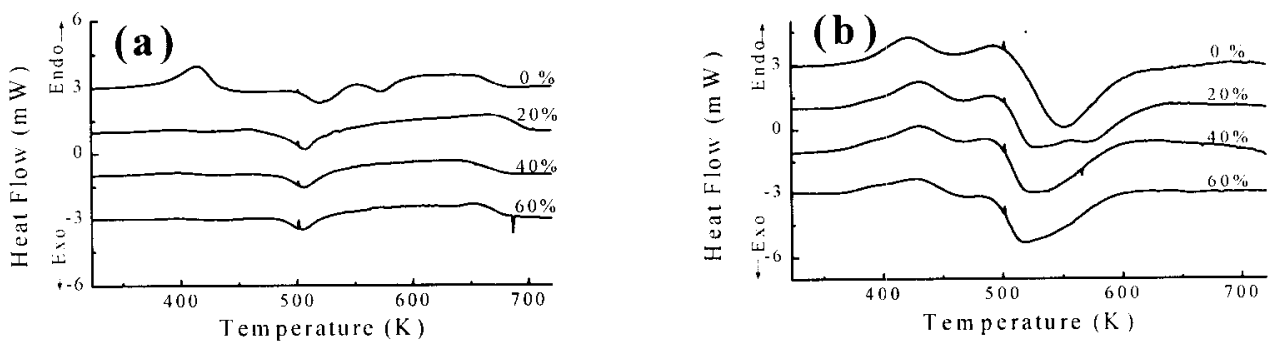

Fig.6 DSC traces of the deformed and natural aged alloys a) alloy D b) alloy B

Dislocations induced by the plastic deformation are favorable nucleation sites for precipitates and short-circuit diffusion paths for solutes. This results in faster and coarser precipitation on dislocation. Moreover, dislocations and other structural defects act also as vacancy sinks, therefore a lower vacancy concentration is available for the matrix precipitation. Due to the strong influence of the vacancy concentration in the precipitation process in $\mathrm{Al}-\mathrm{Zn}-\mathrm{Mg}-\mathrm{Cu}$ alloys, the presence of dislocation influence a large volume of matrix around them. The nucleation of G.P. zones is suppressed in the matrix with very high dislocation concentration.

The DSC results of the $0 \sim 60 \%$ deformed and natural aged alloy $\mathrm{C}$ are shown in Fig. $6 \mathrm{~b}$. The deformed alloys show an endothermic doublet at $380 \sim 430 \mathrm{~K}$ which become more and more obvious with the increase of the deformation amount. The endotherm at $550 \mathrm{~K}$ due to the dissolution of $\eta$ appears in the deformed alloys, and this compensates the exotherm caused by precipitation of the $T$ phase.

The endothermic peak at $420 \sim 430 \mathrm{~K}$ is corresponding to the endotherm in Fig. 3 and caused by the reversion of sub-critical diameter $\mathrm{Al}_{3} \mathrm{Li}$. Then the endotherm at around $380 \mathrm{~K}$ is obviously the dissolution of Zn-rich G.P. zones. Since Li possesses a high vacancy-binding energy of $0.25 \sim$ $0.26 \mathrm{eV}$ and high volume fraction, this lead to a strong tendency for preferential binding between $\mathrm{Li}$ atoms and the quench-in vacancies. The strong trapping of vacancies by $\mathrm{Li}$ atoms decreases the concentration of excess vacancies, and the homogeneous nucleation and precipitation of $\mathrm{Zn}$-rich $\mathrm{G}$. $\mathrm{P}$. zones were suppressed in the Li containing alloys. The plastic deformation introduces in the matrix a high concentration of structural defects, which may provide the heterogeneous nuclei for the $\mathrm{Zn}$-rich G.P. zones. Consequently, the precipitation of smaller $\mathrm{MgZn}_{2}$ phase is encouraged in the deformed alloys as shown in Fig.5.

\section{Hardness response}

The hardness responses of the multi-step aged specimen during the final aging were plotted in Fig. 7. It is seen that the hardness of the Li-free alloy (Fig.7a) decreases continually during the final aging due to the coarsening of the precipitation structure. While for the Li-containing alloys, the hardness increase monotonically with an increase in the amount of pre-deformation. The $60 \%$ cold rolling leads to the peak hardness of alloy $\mathrm{C}$ rising above $180 \mathrm{HV}$ (Fig. $7 \mathrm{~b}$ ).

The precipitation of fine $\mathrm{MgZn}_{2}$ other than fair coarse $\mathrm{T}$ phase, combining with the deformation strengthening contribute to the increase in aging hardening effect. 

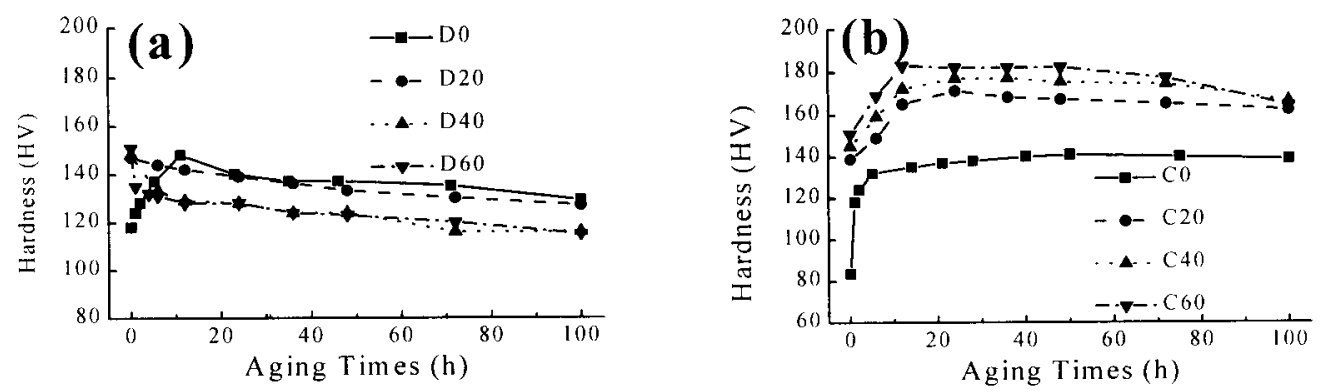

Fig.7 Aging hardening curves of multi-step aged Al-Li-Zn-Mg-Cu alloys a) Alloy D b) Alloy C

\section{Conclusions}

(1) The addition of $1.8 \sim 2.1 \% \mathrm{Li}$ remarkably alter the precipitation behavior of the Al-Zn-Mg-Cu alloy. The $\delta^{\prime}$ phase becomes dominant precipitated phase. The homogeneous precipitation of the $\mathrm{MgZn}_{2}$ phases is suppressed, Instead $\mathrm{T}$ phase precipitates primarily on grain boundaries and provides little strengthening.

(2) The high volume fraction and significant vacancy-binding energy of Li atoms, cause the preferential clustering between $\mathrm{Li}$ atoms and quench-in vacancies, then retard the diffusion of $\mathrm{Zn}$, $\mathrm{Mg}$ atoms, thereby suppress the homogenous nucleation of Zn-rich G.P. zones in the matrix.

(3) In the $\mathrm{Li}$ free alloy, the structural defects with high concentration induced by plastic deformation act as vacancy sinks, suppress the homogeneous nucleation of $\mathrm{Zn}$-rich G.P. zones, and decrease the hardening effect. While in the $\mathrm{Li}$ containing alloys, these defects provide heterogeneous nuclei for the nucleation of G.P. zones and metastable $\mathrm{MgZn} \mathrm{n}_{2}$, and encourage the precipitation of fine $\mathrm{MgZ} \mathrm{n}_{2}$ in the matrix.

(4) A significant aging hardening effect is attained in the deformed Li containing alloys, due to the extra precipitation of fine $\mathrm{MgZn} 2$ in the matrix combined with the deformation hardening.

\section{References}

1. E. S. Balmuth and R. Schmidt, in Aluminum-Lithium Alloys, The Metallurgical Society of AIME, 1981, p69

2. E. S. Balmuth, in the 4th International Conference on Aluminum Alloys, Atlanta: Georgia Institute of Technology, 1994, p82

3. T. H. Sanders and E. A. Starke, in Aluminum-Lithium Alloys, V II, Materials and Component Engineering Publications, 1989, pl

4. R. H. Graham, R. J. Rioja and J. M. Newman, in Aluminum-Lithium, Germany: Oberursel. DGM Informationsgese-llschaftmbH, 1992, p15

5. D. Little, in Aluminum-Lithium Alloys III, London: The Institute of Metals, p15

6. Z. W.Huang, M. H. Loretto and J. White, Materials Science and Technology, V11(1993), p967

7. A. Sodergren and D. J. Lloyd, Acta Metall., V36(1988), p2107

8. S. P. Ringer, B. C. Muddle and I. J. Polmear, Metall. Trans. 26A(1995), p1659

9. M. R. Edwards and M. J. Whiley, in the 4th International Conference on Aluminum Alloys, Atlanta: Georgia Institute of Technology, 1994, p473

10. W. A. Cassada, G. J. Shiflet and E. A. Starke Jr., Metall. Trans. 26A(1995), p299

11.S. Ceresara and P. Fiorini, Mater. Sci. Engng, 10(1972), p205

12.E. Balmuth, Scripta metall., 18(1984), p301

Corresponding author:

Prof.C.Q.Chen E-mail: CQChen@buaa.edu.cn 
Aluminium Alloys - Their Physical and Mechanical Properties

10.4028/www.scientific.net/MSF.331-337

Mechanism of Nucleation and Precipitation in Li Containing Al-Zn-Mg-Cu Alloys

10.4028/www.scientific.net/MSF.331-337.1061 